\section{Nanocrystal-based hybrid white light generation with tunable colour parameters}

To cite this article: S Nizamoglu and H V Demir 2007 J. Opt. A: Pure Appl. Opt. 9 S419

View the article online for updates and enhancements.

\section{Related content}

White light generation using $\mathrm{CdSe} / \mathrm{ZnS}$ core-shell nanocrystals hybridized withlnGaN/GaN light emitting diodes S Nizamoglu, T Ozel, E Sari et al.

White light generation tuned by dual hybridization of nanocrystals and conjugated polymers

Hilmi Volkan Demir, Sedat Nizamoglu, Tuncay Ozel et al.

Hybrid white light sources based on layerby-layer assembly of nanocrystals on

near-UVemitting diodes

Sedat Nizamoglu and Hilmi Volkan Demir

\section{Recent citations}

- White emitting CdS quantum dot
$\frac{\text { nanoluminophores hybridized on near- }}{\underline{\text { ultraviolet LEDs for high-quality white light }}}$
$\frac{\text { generation and tuning }}{\text { Sedat Nizamoglu et al }}$
- White light generation by resonant
$\frac{\text { nonradiative energy transfer from epitaxial }}{\text { InGaN/GaN quantum wells to colloidal }}$
$\frac{\text { CdSe/ZnS core/shell quantum dots }}{\text { Sedat Nizamoglu et al }}$
- Tuning shades of white light with multi-
$\frac{\text { color quantum-dot-quantum-well emitters }}{\text { based on onion-like CdSe-ZnS }}$
$\frac{\text { heteronanocrystals }}{\text { Hilmi Volkan Demir et al }}$




\title{
Nanocrystal-based hybrid white light generation with tunable colour parameters
}

\author{
S Nizamoglu ${ }^{1,3}$ and H V Demir ${ }^{1,2,3}$ \\ ${ }^{1}$ Department of Physics, Bilkent University, Ankara, TR-06800, Turkey \\ 2 Department of Electrical and Electronics Engineering, Bilkent University, Ankara, \\ TR-06800, Turkey \\ ${ }^{3}$ Nanotechnology Research Center, Bilkent University, Ankara, TR-06800, Turkey \\ E-mail: volkan@bilkent.edu.tr (H V Demir)
}

Received 31 January 2007, accepted for publication 28 March 2007

Published 24 August 2007

Online at stacks.iop.org/JOptA/9/S419

\begin{abstract}
We present the hybridization of CdSe/ZnS core-shell nanocrystals (NCs) on InGaN/GaN based blue/near-UV LEDs to generate light widely tunable across the visible spectral range and especially within the white region of the CIE (1931) chromaticity diagram. We report on the design, growth, fabrication and characterization of these hybrid NC-LEDs. In 26 NC-LED samples, we experimentally show the effect of the NC concentration and NC film thickness on tuning the colour properties of the generated light (tristimulus coordinates, colour rendering index and correlated temperature) and further compare layer by layer assembly and blending of NCs for integration in LEDs. With greatly tunable colour properties, these hybrid white light sources hold promise for future lighting and display applications.
\end{abstract}

Keywords: nanocrystals, white light generation, LEDs

(Some figures in this article are in colour only in the electronic version)

\begin{abstract}
Within the next five years, it is likely that white light emitting diodes (WLEDs) will be used for all external lighting functions on vehicles [1]. Because of such widescale potential use, WLEDs have attracted both scientific attention and commercial interest [2]. Different approaches for white light generation such as multi-chip WLEDs, monolithic WLEDs and colour-conversion WLEDs have been extensively investigated [3-5]. Among these, multi-chip white LEDs (and monolithic WLEDs, in principle, for the same matter) tend to exhibit higher electrical-to-light conversion efficiencies when compared with colour-conversion WLEDs, for the multi-chip WLEDs do not have additional energy losses caused by the Stokes shift and nonradiative recombination, unlike in the phosphor coating of colour-conversion WLEDs. Additionally, multi-chip WLEDs do not suffer ageing problems related to the phosphor, which affects the lifetime of colour-conversion WLEDs [6]. However, for multi-chip WLEDs, the driving electric circuit is typically comparatively complex for general illumination purposes, leading to increased costs [5]. As a result, the colour-conversion approach provides an advantage specifically in having simple circuits (and thus reduced
\end{abstract}

cost) when compared to the multi-chip WLED approach. Today, using the colour-conversion technique, phosphorbased WLEDs have been widely commercialized and are currently in use. In phosphor-based colour conversion, however, difficulties in controlling granule size systematically, and mixing and depositing films uniformly pose the most fundamental disadvantages, which result in undesired visible colour variations [7].

As an alternative approach, nanocrystals (NCs) have recently been used for colour conversion in white light generation. To date we have introduced white light generation using $\mathrm{CdSe} / \mathrm{ZnS}$ core-shell nanocrystals of single, dual, trio and quadruple combinations hybridized with blue InGaN/GaN LEDs [8,9]. Also, a blue/green two-wavelength InGaN/GaN LED coated with a single type of red $\mathrm{NC}$ and a blue InGaN/GaN LED with a single type of yellow NC and a dual type of red and green NCs have been reported [10-12]. In this paper, we present the hybridization of $\mathrm{CdSe} / \mathrm{ZnS}$ coreshell nanocrystals (NCs) on InGaN/GaN-based blue/near-UV LEDs to generate light widely tunable across the visible spectral range and especially within the white region of the 

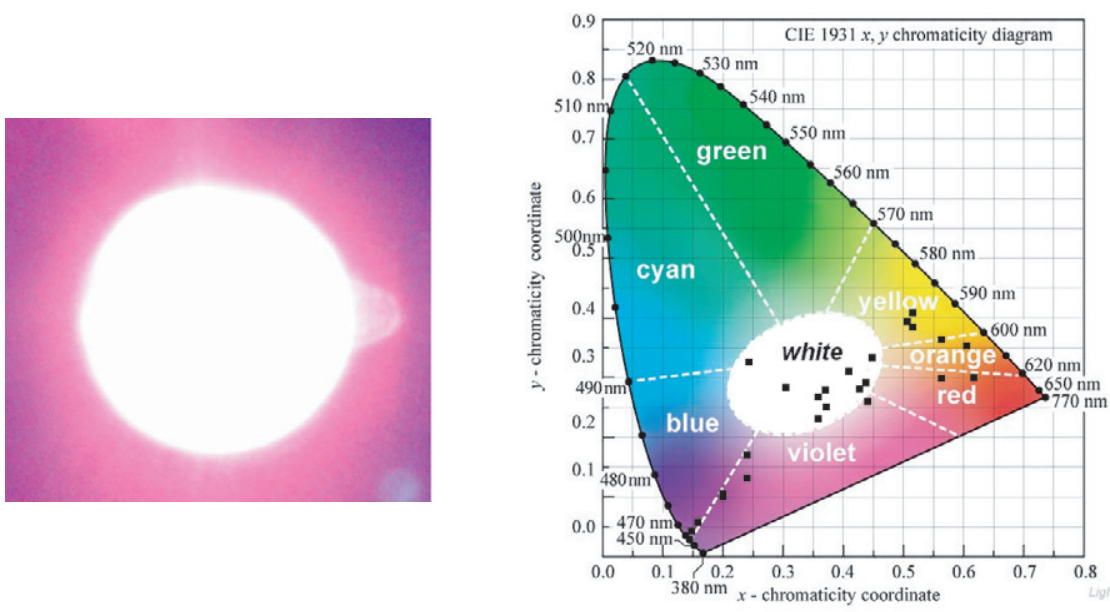

Figure 1. A photograph of white light generation from one of our hybrid white NC-WLEDs (left) and tristimulus coordinates of our hybrid NC-WLEDs on the CIE (1931) chromaticity diagram.

CIE (1931) chromaticity diagram, as shown as an exemplary implementation in figure 1 (left). Here we report on the design, growth, fabrication and characterization of these hybrid NC-LEDs. In 26 of our NC-LED samples, we experimentally show the effect of the $\mathrm{NC}$ concentration and $\mathrm{NC}$ film thickness on tuning the colour properties of the generated light (tristimulus coordinates, colour rendering index and correlated temperature), as shown on the CIE chromacity diagram in figure 1 (right). We further compare layer by layer assembly and blending of NCs for integration on LEDs. Using combinations of nanocrystals and organizing them mixed and/or unmixed in layers, we tune the colour parameters of the generated light.

We adjust the colour properties (tristimulus coordinates, correlated colour temperature and colour rendering index) of the generated white light by setting the device parameters including the thickness and order of the NC films and the type and concentration of NCs. The order of NC films, with a different $\mathrm{NC}$ type in each film, determines the level of reabsorption of the photons emitted by the preceding $\mathrm{NC}$ layers. The film thickness and NC density affect the level of conversion from incident photons to emitted/transmitted photons for each NC layer. The type of NCs determines the intervals of the visible spectrum designed to contribute to white light. Therefore, the ability to control such hybrid device parameters makes it possible to generate the intended white light spectrum in the visible.

We use four types of $\mathrm{CdSe} / \mathrm{ZnS}$ core-shell NCs from Evident Technologies. Their photoluminescence in the visible spectral range corresponds to cyan, green, yellow and red. The $\mathrm{NC}$ diameters range from 1.9 to $5.2 \mathrm{~nm}$. We use these NCs blended in host resin with a size distribution of $\pm 5 \%$. We use both PMMA and UV-curable resin to make NC films that enable us to adjust the concentration. When we hybridize the NCs in toluene and host polymer on LEDs, since the toluene solvent evaporates, given the total number of NCs in the solution, the amount of polymer controllably determines the NC concentration. Usually the NC concentration we use for hybridization ranges from 3.04 to $140 \mathrm{nmol} / 1 \mathrm{ml}$ of resin. We can use NC film thickness ranging from a few micrometre

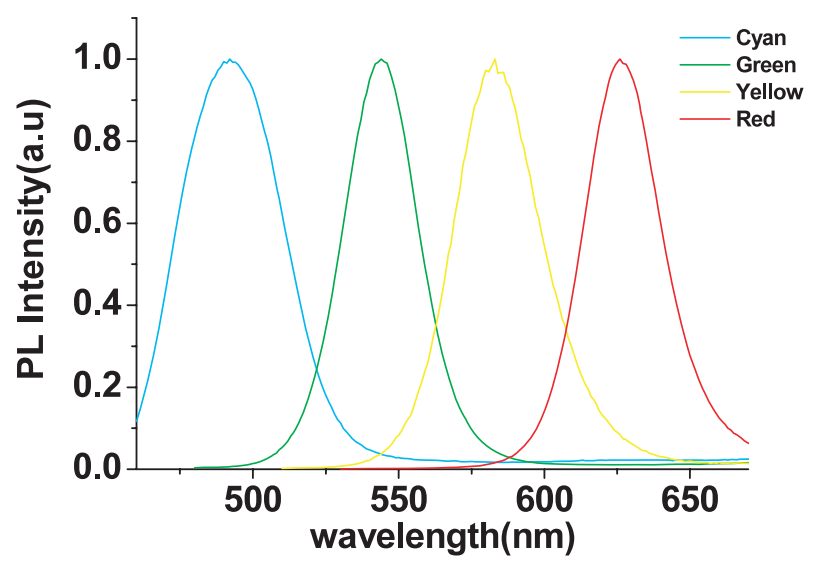

Figure 2. Photoluminescence spectra of our $\mathrm{CdSe}-\mathrm{ZnS}$ core-shell nanocrystals in host polymer.

to $1700 \mu \mathrm{m}$, depending on the concentration of NC film. Our cyan, green, yellow and red NCs exhibit photoluminescence (PL) peaks at 500, 540, 580 and $620 \mathrm{~nm}$, respectively, as characterized at our labs [8] and shown here in figure 2.

We use an n-UV LED and two types of blue InGaN/GaN LEDs for integration. The n-UV LED has a peak electroluminescence at $383 \mathrm{~nm}$, one of the blue LEDs at $440 \mathrm{~nm}$ and the other at $452 \mathrm{~nm}$. We use an epitaxial layer design similar for the n-UV LED and the two blue LEDs. The difference between the n-UV and blue LEDs is the epitaxial growth temperatures and the thickness of the active layers (2$3 \mathrm{~nm}$ for the n-UV LED and 4-5 nm for the blue LEDs). The difference between the two blue LEDs is only the change of the epitaxial growth temperatures of their respective active layers. The design of these InGaN/GaN LEDs is presented along with the thickness of each epitaxial layer in figure 3 .

We use a GaN dedicated metal-organic chemical vapour deposition (MOCVD) system (Aixtron RF200/4 RF-S) for the growth of our epitaxial layers at Bilkent University Nanotechnology Research Center. We start with a $14 \mathrm{~nm}$ thick GaN nucleation layer and a $200 \mathrm{~nm}$ thick GaN buffer layer to increase the crystal quality of the device epitaxial layers. 


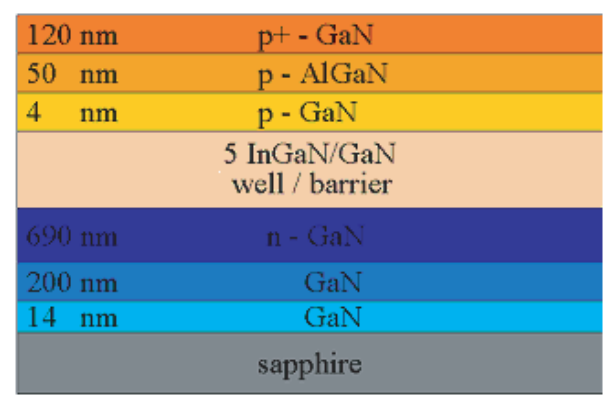

Figure 3. Epitaxial structure of our blue LEDs (not drawn to scale) [8].

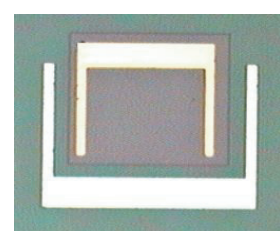

(a)

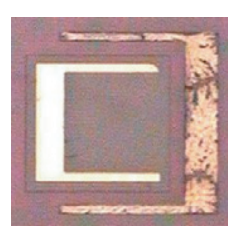

(b)

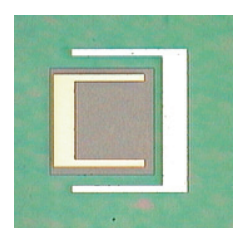

(c)
Figure 4. Micrographs of our fabricated n-UV and blue LEDs: (a) with $\lambda_{\mathrm{EL}}=383 \mathrm{~nm}$, (b) with $\lambda_{\mathrm{EL}}=440 \mathrm{~nm}$ and (c) with $\lambda_{\mathrm{EL}}=452 \mathrm{~nm}$.

Subsequently, we grow a $690 \mathrm{~nm}$ thick, Si doped n-type contact layer. We then continue with the epi-growth of five InGaN wells and $\mathrm{GaN}$ barriers as the active layers of our LEDs. The growth temperature of this active region determines the amount of In incorporation into the wells, which in turn adjusts the emission peak wavelength. Therefore, we use distinct active region growth temperatures for our LEDs. The n-UV LED active layer is grown at $720^{\circ} \mathrm{C}$ for $383 \mathrm{~nm}$ EL peak, while one of the blue LEDs is grown at $682^{\circ} \mathrm{C}$ for $440 \mathrm{~nm}$ EL peak and the other blue LED at $661{ }^{\circ} \mathrm{C}$ for $452 \mathrm{~nm}$ EL peak. Finally, we finish our growth with p-type layers that consist of $\mathrm{Mg}$-doped, $50 \mathrm{~nm}$ thick $\mathrm{Al}_{0.1} \mathrm{Ga}_{0.9} \mathrm{~N}$ and $120 \mathrm{~nm}$ thick $\mathrm{GaN}$ layers as the contact cap. Following the growth, we activate $\mathrm{Mg}$ dopants at $750{ }^{\circ} \mathrm{C}$ for $15 \mathrm{~min}$.

In the device fabrication, we use standard semiconductor processing including photolithography, thermal evaporator (metallization), reactive ion etch (RIE) and rapid thermal annealing. Our p-contacts consist of Ni/Au $(15 \mathrm{~nm} / 100 \mathrm{~nm})$ and are annealed at $700{ }^{\circ} \mathrm{C}$ for $30 \mathrm{~s}$ under $\mathrm{N}_{2}$ purge. On the other hand, our $\mathrm{n}$-contacts consist of Ti/Al $(100 \mathrm{~nm} / 2500 \mathrm{~nm})$ and are annealed at $600^{\circ} \mathrm{C}$ for 1 min under $\mathrm{N}_{2}$ purge. The topview micrographs of our fabricated $\mathrm{n}-\mathrm{UV}$ and blue LEDs (with $\lambda_{\mathrm{EL}}=383 \mathrm{~nm}$ in (a), $\lambda_{\mathrm{EL}}=440 \mathrm{~nm}$ in (b) and $\lambda_{\mathrm{EL}}=452 \mathrm{~nm}$ in (c)) are shown in figure 4. For on-chip integration, following the surface treatment, we hybridize the LED top surface with various types of NCs in host polymer. Our n-UV LED and blue LEDs have turn-on voltages approximately at 6 and $4 \mathrm{~V}$, and electroluminescence (EL) peak wavelengths at 383, 440 and $452 \mathrm{~nm}$, respectively, as shown in figure 5 .

The operating principle of these hybrid NC-WLEDs relies on the hybrid use of the LED as the pump light source and the integrated $\mathrm{NC}$ film as the photoluminescent layer. When electrically driven, the LED optically pumps the NCs. The photoluminescence of these NCs and the electroluminescence of the LED consequently contribute together to the white light generation. Here with the ability to tune the NC photoluminescence peaks across the visible (using the size effect) and with the right choice of NC combinations, we cover the visible spectrum from blue to red with a necessary spectral power distribution. Furthermore, with the small overlap between the NC emission and absorption spectra, we conveniently modify the white light spectrum as desired with the addition of NCs.

Table 1 lists 26 different samples of our hybrid light sources along with their corresponding tristimulus coordinates, correlated colour temperature and colour rendering index. Sample 1 shows one of the blue LEDs with $452 \mathrm{~nm}$ electroluminescence peak as the starting platform. For samples 2-6, we hybridize yellow NCs on this blue LED. In sample 2 , we integrate $25 \mu \mathrm{l} \mathrm{NCs}$ in toluene with $3.1 \mu \mathrm{l}$ PMMA solution corresponding to a concentration of $2.36 \mu \mathrm{mol} \mathrm{ml}^{-1}$. For each subsequent sample (from sample 2 to sample 6), we increase the NC solution by multiples of $25 \mu \mathrm{l}$ and PMMA by $3.1 \mu 1$. For sample 6 , we end up with $150 \mu \mathrm{l}$ NC solution and $18.75 \mu$ l PMMA, corresponding to a final concentration of $2.36 \mu \mathrm{mol} \mathrm{ml} l^{-1}$. Consequently, on the CIE chromaticity diagram, the $(x, y)$ tristimulus coordinates of these samples begin with $(0.14,0.03)$ on the blue edge for $452 \mathrm{~nm}$ and reach $(0.43,0.28)$ in the white region. The correlated colour temperature ranges from cool white colours to warm white colours as we increase the hybridized NCs solution. Furthermore, the colour rendering index starts with -51.5 , increases in each step and reaches 15.8 as a dichromatic source. Therefore, we observe experimentally that the thickness of the hybridized NC thin films significantly shifts the colour parameters of the resulting hybrid LEDs. Figure 6 shows the optical spectrum of sample 6 to observe the increase in the yellow peak with respect to electroluminescence of blue LED.

For samples 7-9, we increase green $\mathrm{NC}$ volume in toluene by $25 \mu \mathrm{l}$ and PMMA by $3.1 \mu \mathrm{l}$, corresponding to a concentration of $5.59 \mu \mathrm{mol} \mathrm{ml}^{-1}$, and on top of the green $\mathrm{NC}$ film we place $150 \mu \mathrm{l}$ yellow NCs and $18.75 \mu \mathrm{l}$ PMMA having a concentration of $2.36 \mu \mathrm{mol} \mathrm{ml}{ }^{-1}$. As a result, the tristimulus coordinates of these samples move from $(0.44,0.29)$ to $(0.52$, 0.37). The corresponding correlated colour temperatures move towards warm white to $1754 \mathrm{~K}$.

When $150 \mu$ l yellow NCs and $18.75 \mu$ l PMMA with a concentration of $2.36 \mu \mathrm{mol} \mathrm{ml} l^{-1}$ are hybridized on the blue LED at $452 \mathrm{~nm}$, the colour rendering index is only 15.8 (due to the dichromacity of the source). However, when $75 \mu \mathrm{l}$ green $\mathrm{NC}$ and $9.3 \mu \mathrm{l}$ PMMA with a concentration of $5.59 \mu \mathrm{mol} \mathrm{ml}^{-1}$ and $150 \mu \mathrm{l}$ yellow NC and $18.75 \mu \mathrm{l}$ PMMA with a concentration of $2.36 \mu \mathrm{mol} \mathrm{ml} l^{-1}$ are hybridized layer by layer in the respective order, the colour rendering index becomes 50.7 (because of the trichromaticity of the source). Figure 7 shows the optical spectrum of this hybrid LED (sample 9). For samples 10 and 11, we similarly observe an increase in correlated colour temperature and colour rendering index by adding red NCs instead of green NCs.

For samples 12-15, we hybridize the cyan NC film first and then add $150 \mu \mathrm{l}$ yellow NCs and $18.75 \mu \mathrm{l}$ PMMA having a concentration of $2.36 \mu \mathrm{mol} \mathrm{ml}^{-1}$ on top of it. In each sample, we add $25 \mu \mathrm{l}$ cyan NCs in toluene and $3.1 \mu 1$ PMMA, corresponding to an additional concentration 


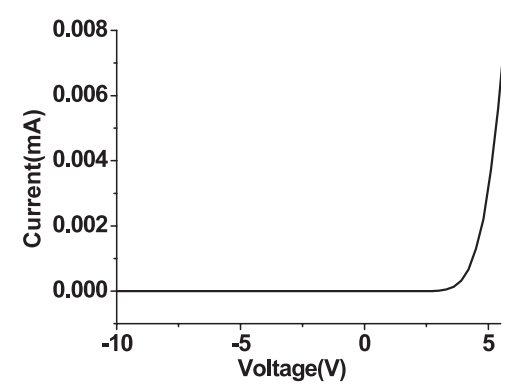

(a)

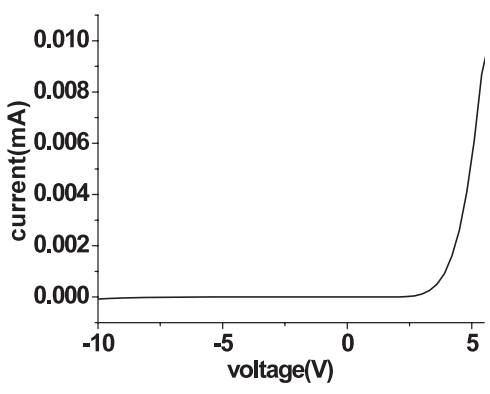

(c)

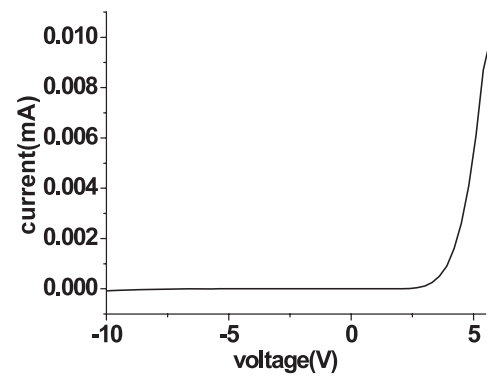

(b)

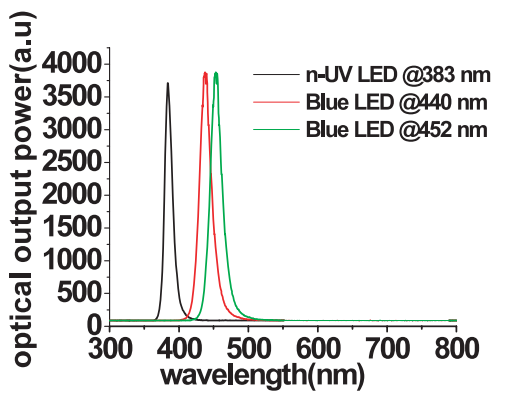

(d)

Figure 5. (a) $I V$ of $\mathrm{n}-\mathrm{UV} \operatorname{LED}\left(\lambda_{\mathrm{EL}}=383 \mathrm{~nm}\right)$, (b) $I V$ of blue LED $\left(\lambda_{\mathrm{EL}}=440 \mathrm{~nm}\right)$, (c) $I V$ of blue LED $\left(\lambda_{\mathrm{EL}}=452 \mathrm{~nm}\right)$ and (d) electroluminescence of n-UV LED and two blue LEDs.

Table 1. Our hybrid NC-WLED sample characteristics. (C: cyan NC; G: green NC; Y: yellow NC; R: red NC; * denotes blended NC hybridization.)

\begin{tabular}{|c|c|c|c|c|c|c|c|}
\hline $\begin{array}{l}\text { Sample } \\
\#\end{array}$ & $\begin{array}{l}\text { Hybridized } \\
\text { nanocrystals }\end{array}$ & $\begin{array}{l}\text { LED } \\
\lambda_{\mathrm{EL}}(\mathrm{nm})\end{array}$ & $\begin{array}{l}\text { Concentration } \\
\left(\mu \mathrm{mol} \mathrm{ml} l^{-1}\right)\end{array}$ & $x$ & $y$ & $\begin{array}{l}T_{\mathrm{c}} \\
(\mathrm{K})\end{array}$ & $R_{\mathrm{a}}$ \\
\hline 1 & - & 452 & - & 0.14 & 0.03 & 34367 & -51.5 \\
\hline 2 & $\mathrm{Y}$ & 452 & 2.36 & 0.15 & 0.04 & 34367 & -40.2 \\
\hline 3 & $\mathrm{Y}$ & 452 & 2.36 & 0.16 & 0.06 & 34367 & -28.6 \\
\hline 4 & $\mathrm{Y}$ & 452 & 2.36 & 0.20 & 0.10 & 34366 & -10.1 \\
\hline 5 & $\mathrm{Y}$ & 452 & 2.36 & 0.24 & 0.13 & 34366 & -3.8 \\
\hline 6 & $\mathrm{Y}$ & 452 & 2.36 & 0.43 & 0.28 & 1882 & 15.8 \\
\hline 7 & $\mathrm{G}, \mathrm{Y}$ & 452 & $5.59,2.36$ & 0.44 & 0.29 & 1989 & 37.5 \\
\hline 8 & $\mathrm{G}, \mathrm{Y}$ & 452 & $5.59,2.36$ & 0.45 & 0.33 & 2165 & 54.5 \\
\hline 9 & $\mathrm{G}, \mathrm{Y}$ & 452 & $5.59,2.36$ & 0.52 & 0.37 & 1754 & 50.2 \\
\hline 10 & $\mathrm{R}, \mathrm{Y}$ & 452 & $0.88,2.36$ & 0.57 & 0.30 & 1121 & 42.2 \\
\hline 11 & $\mathrm{R}, \mathrm{Y}$ & 452 & $0.88,2.36$ & 0.62 & 0.30 & 1000 & 50.7 \\
\hline 12 & $\mathrm{C}, \mathrm{Y}$ & 452 & $12.05,2.36$ & 0.24 & 0.13 & 34366 & -3.4 \\
\hline 13 & C, Y & 452 & $12.05,2.36$ & 0.36 & 0.23 & 2651 & 32.4 \\
\hline 14 & $\mathrm{C}, \mathrm{Y}$ & 452 & $12.05,2.36$ & 0.36 & 0.27 & 3228 & 48.3 \\
\hline 15 & $\mathrm{C}, \mathrm{Y}$ & 452 & $12.05,2.36$ & 0.42 & 0.31 & 2311 & 50.2 \\
\hline 16 & $\mathrm{Y}$ & 440 & 0.11 & 0.37 & 0.25 & 2692 & 14.6 \\
\hline 17 & $\mathrm{C}, \mathrm{Y}$ & 440 & $0.37,0.11$ & 0.37 & 0.28 & 3246 & 19.6 \\
\hline 18 & $\mathrm{G}, \mathrm{Y}, \mathrm{R}$ & 452 & $0.27,0.11,0.025$ & 0.30 & 0.28 & 7521 & 40.9 \\
\hline 19 & $\mathrm{C}, \mathrm{G}, \mathrm{Y}, \mathrm{R}$ & 452 & $0.37,0.27,0.1,0.025$ & 0.24 & 0.33 & 11171 & 71.0 \\
\hline $20^{*}$ & $\mathrm{C}, \mathrm{Y}, \mathrm{R}$ & 452 & $2.54,0.19,0.06$ & 0.44 & 0.26 & 1625 & 38.8 \\
\hline 21 & $\mathrm{C}, \mathrm{Y}, \mathrm{R}$ & 452 & $2.8,2.8,2.8$ & 0.20 & 0.10 & 34366 & 1.9 \\
\hline 22 & $\mathrm{C}, \mathrm{Y}, \mathrm{R}$ & 383 & $2.8,2.8,2.8$ & 0.51 & 0.39 & 1979 & 71.9 \\
\hline $23^{*}$ & C, Y, R & 383 & $2.54,0.19,0.06$ & 0.61 & 0.36 & 1238 & 74.3 \\
\hline 24 & $\mathrm{C}, \mathrm{R}$ & 452 & $2.8,2.8$ & 0.20 & 0.11 & 34367 & 4.0 \\
\hline $25^{*}$ & $\mathrm{C}, \mathrm{R}$ & 452 & $2.73,0.06$ & 0.24 & 0.13 & 34366 & -13.8 \\
\hline $26^{*}$ & $\mathrm{C}, \mathrm{R}$ & 383 & $2.73,0.06$ & 0.57 & 0.37 & 1477 & 47.6 \\
\hline 27 & $\mathrm{C}, \mathrm{R}$ & 383 & $2.8,2.8$ & 0.52 & 0.41 & 1977 & 42.1 \\
\hline
\end{tabular}

of $12.05 \mu \mathrm{mol} \mathrm{ml}{ }^{-1}$. By increasing the incorporation of cyan NCs, the tristimulus coordinates move closer to the cyan part of the CIE chromaticity diagram, which would imply the correlated colour temperature to increase. However, on the contrary, in our samples we observe that the correlated colour temperature of our hybrid NC-LEDs decreases and 


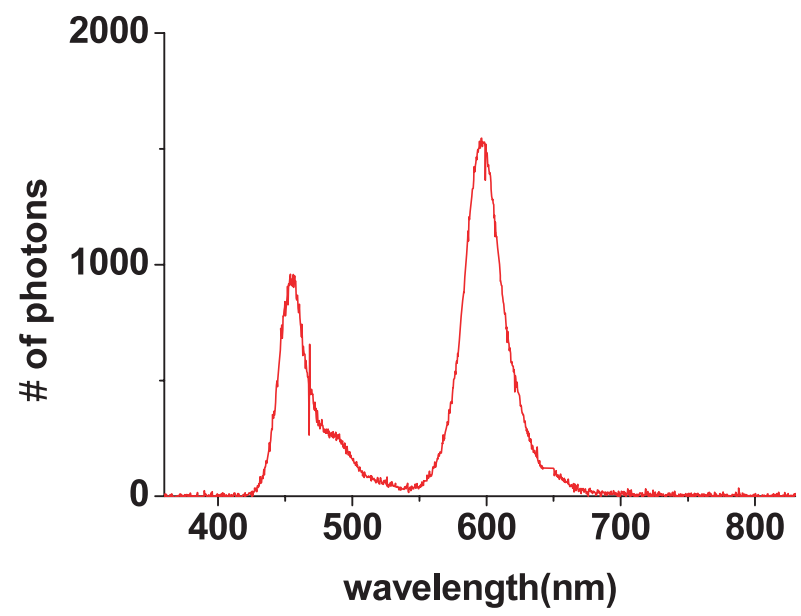

Figure 6. Electroluminescence spectrum of $150 \mu \mathrm{l}$ yellow NCs $\left(\lambda_{\mathrm{PL}}=580 \mathrm{~nm}\right)$ and $18.75 \mu 1$ PMMA corresponding to a film concentration of $12.05 \mu \mathrm{mol} \mathrm{ml}^{-1}$ hybridized on blue LED $\left(\lambda_{\mathrm{EL}}=452 \mathrm{~nm}\right)$ measured at an injection current level of $5 \mathrm{~mA}$ at room temperature.

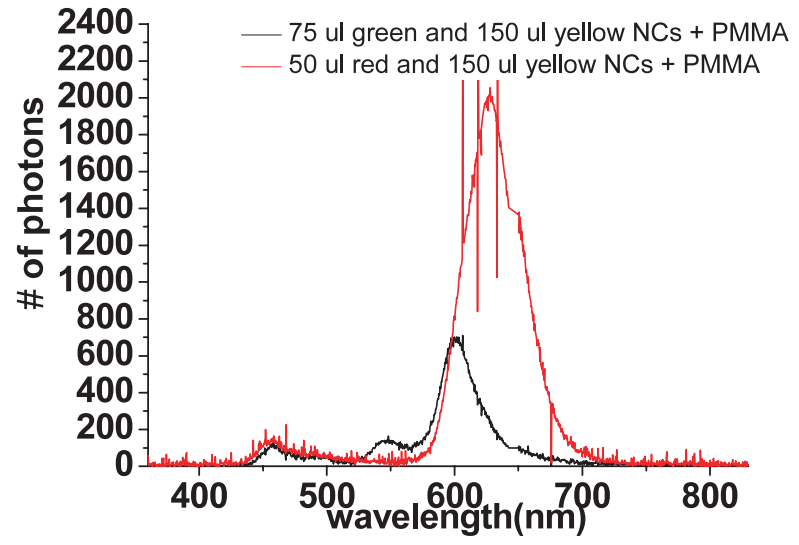

Figure 7. Electroluminescence spectrum of $75 \mu 1$ green $\mathrm{NC}$ and $9.3 \mu 1$ PMMA corresponding to a film concentration of $5.59 \mu \mathrm{mol} \mathrm{ml}^{-1}$ and $150 \mu \mathrm{l}$ yellow NCs $\left(\lambda_{\mathrm{PL}}=540\right.$ and $\left.580 \mathrm{~nm}\right)$ and $18.75 \mu \mathrm{l}$ PMMA corresponding to a film concentration of $12.05 \mu \mathrm{mol} \mathrm{ml}{ }^{-1}$ hybridized with blue $\operatorname{LED}\left(\lambda_{\mathrm{EL}}=452 \mathrm{~nm}\right)$ at an injection current level of $5 \mathrm{~mA}$ and the electroluminescence spectrum of $50 \mu 1$ red NC and $6.2 \mu 1$ PMMA corresponding to a film concentration of $0.88 \mu \mathrm{mol} \mathrm{ml}^{-1}$ and $150 \mu 1$ yellow NCs $\left(\lambda_{\mathrm{PL}}=620\right.$ and $580 \mathrm{~nm}$ ) and $18.75 \mu$ l PMMA corresponding to a film concentration of $12.05 \mu \mathrm{mol} \mathrm{ml}{ }^{-1}$ hybridized on blue LED $\left(\lambda_{\mathrm{EL}}=452 \mathrm{~nm}\right)$ measured at an injection current level of $5 \mathrm{~mA}$ at room temperature.

becomes a warmer light source. According to our observations, this behaviour stems from the reabsorption of the photons generated by the cyan NCs in the top yellow NC film. Figure 8 shows the optical spectrum of $75 \mu \mathrm{l}$ cyan and $9.3 \mu \mathrm{l}$ PMMA corresponding to a concentration of $12.05 \mu \mathrm{mol} \mathrm{ml}^{-1}$ and $150 \mu \mathrm{l}$ yellow NCs and $18.75 \mu \mathrm{l}$ PMMA having a concentration of $2.36 \mu \mathrm{mol} \mathrm{ml}{ }^{-1}$ hybridized on the blue LED with the peak electroluminescence of $452 \mathrm{~nm}$. In table 1, samples 16-19 are also discussed in our previous work [8].

For samples 20-27, we incorporate NCs either blended in a mixture or assembled layer by layer. The samples indicated with $*$ in table 1 are those that are directly hybridized by

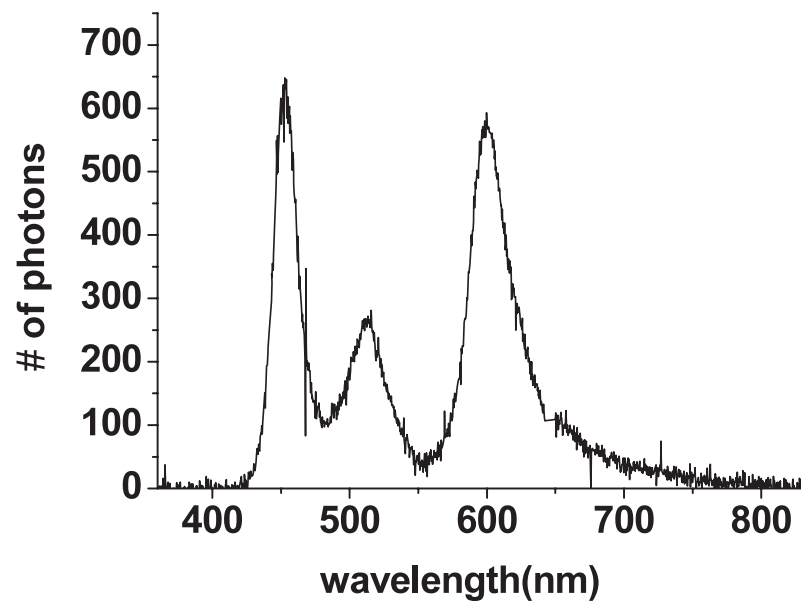

Figure 8. Electroluminescence spectrum of $75 \mu 1$ cyan $\mathrm{NC}$ and $9.3 \mu 1$ PMMA, corresponding to a film concentration of $12.05 \mu \mathrm{mol} \mathrm{ml}^{-1}$, and $150 \mu 1$ yellow NCs $\left(\lambda_{\mathrm{PL}}=500\right.$ and $\left.580 \mathrm{~nm}\right)$ and $18.75 \mu 1$ PMMA, corresponding to a film concentration of $12.05 \mu \mathrm{mol} \mathrm{ml}{ }^{-1}$, hybridized on blue $\operatorname{LED}\left(\lambda_{\mathrm{EL}}=452 \mathrm{~nm}\right)$ measured at an injection current level of $5 \mathrm{~mA}$ at room temperature.

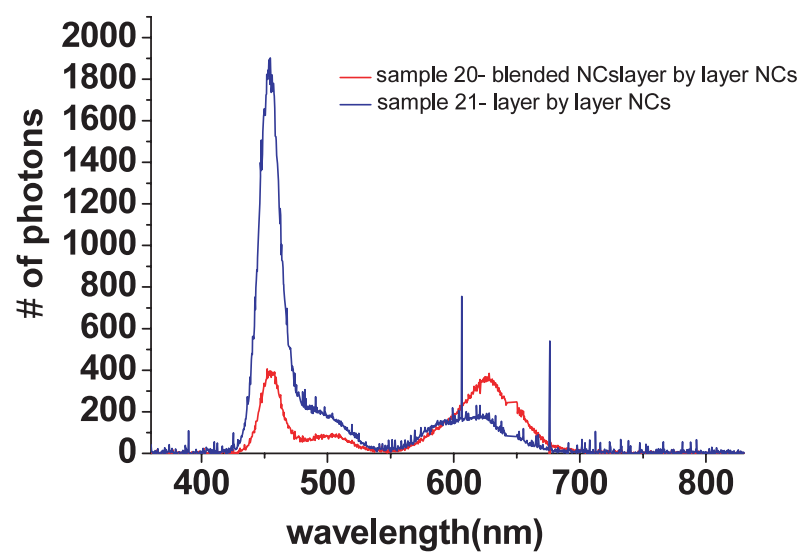

Figure 9. Electroluminescence spectra of samples 20 and 21. Sample 20 consists of a blended mixture of $75 \mu \mathrm{l}$ cyan NC, $25 \mu 1$ yellow NC and $25 \mu 1 \mathrm{red} \mathrm{NC}\left(\lambda_{\mathrm{PL}}=540,580\right.$ and $\left.620 \mathrm{~nm}\right)$ and 2, 6 and $80 \mu 1$ PMMA mixtures, respectively, corresponding to film concentrations of $2.54,0.19$ and $0.06 \mu \mathrm{mol} \mathrm{ml}^{-1}$. Sample 21 consists of layer by layer hybridization of $75 \mu \mathrm{l}$ cyan NC, $25 \mu \mathrm{l}$ yellow NC and $25 \mu \mathrm{l}$ red $\mathrm{NC}\left(\lambda_{\mathrm{PL}}=540,580\right.$ and $\left.620 \mathrm{~nm}\right)$ and $88 \mu 1$ PMMA, corresponding to a film concentration of $2.8 \mu \mathrm{mol} \mathrm{ml}^{-1}$, respectively.

blending all the NCs as a mixture and integrated on the LED (rather than placing layer by layer). To compare the optical properties of these two cases, we select samples 20 and 21. Sample 20 consists of blended cyan, yellow and red NCs. On the other hand, for sample 21, we integrate first the red NC film, on top of which comes the yellow NC film and then finally the cyan NC film to prevent the reabsorbtion of the generated photon by the subsequent films. For each sample, the number of NCs per unit volume (NC concentration) is approximately constant. Figure 9 shows the optical spectrum of both samples 20 and 21. Although the red peak is higher in sample 20, its cyan peak is lower compared to sample 21 . This is because the photoluminescence of the cyan NCs has the probability to be reabsorbed by the red and yellow NCs, which reduces 
the cyan peak in the blended case in sample 20. Additionally, red and yellow NCs can be further pumped also by the photon emitted from the cyan NCs, increasing the red peak. However, in layer by layer assembly in sample 21 , since the cyan NC film is on the top, there is no probability of reabsorption of photoluminescence of cyan NCs.

In conclusion, we demonstrated the hybridization of $\mathrm{CdSe} / \mathrm{ZnS}$ core-shell nanocrystals on InGaN/GaN based blue/near-UV LED to tune colour properties (tristimulus coordinates, colour correlated temperature and colour rendering index) of the generated light across the visible and within the white region of the CIE choromacity diagram. Working on 26 samples of hybrid NC-LEDs, we experimentally investigated the effects of NC concentrations and NC film thicknesses on tuning these colour properties and discussed layer by layer assembly of NCs as opposed to blending in a mixture. We concluded that these hybrid white light sources hold great promise for future lighting and display applications with their widely tunable colour properties.

\section{Acknowledgments}

This work is supported by EU-PHOREMOST Network of Excellence 511616 and Marie Curie European Reintegration Grant MOON 021391 within the 6th European Community Framework Program and TUBITAK under Project Nos. EEEAG 106E020, 104E114, 105E065, and 105E066.
HVD and SN also acknowledge additional support from the Turkish National Academy of Sciences Distinguished Young Scientist Award and TUBITAK Fellowship programs.

\section{References}

[1] Landau S and Erion J 2007 Nat. Photon. 1 31-2

[2] Arik M, Petroskf J and Weavery S 2002 Inter Society Conf. on Thermal Phenomena pp 112-20

[3] Nakamura S and Fasol G 1997 The Blue Laser Diode (Berlin: Springer)

[4] Schubert E F 2006 Light-Emitting Diodes (Cambridge: Cambridge University Press)

[5] Yamada M, Narukawa Y, Tamaki H, Murazaki Y and Mukai T 2005 IEICE Trans. Electron. E88-C 9 1860-71

[6] Zukauskas A, Shur M S and Gaska R 2001 MRS Bull. 26 764-9

[7] Heliotis G, Gu E, Griffin C, Jeon C W, Stavrinou P N, Dawson M D and Bradley D D C 2006 J. Opt. A: Pure Appl. Opt. 8 445-9

[8] Nizamoglu S, Ozel T, Sari E and Demir H V 2007 Nanotechnology 18065709

[9] Nizamoglu S, Ozel T, Sari E and Demir H V 2006 IEEE COMMAD Conf. on Optoelectronic and Microelectronic Materials and Devices (Perth, Australia) WO-A5

[10] Chen H, Yeh D, Lu C, Huang C, Shiao W, Huang J, Yang C C, Liu I and Su W 2006 IEEE Photon. Technol. Lett. 18 1430-2

[11] Chen H, Hsu C and Hong H 2006 IEEE Photon. Technol. Lett. 18 193-5

[12] Petruska M A, Koleske D D, Crawford M H and Klimov V I 2006 Nano Lett. 6 1396-400 